\title{
Objeto, corpo, espaço, e... Provocações sobre dramaturgia e formação no Teatro de Animação ${ }^{1}$
}

Object, body, space, and... Provocations on dramaturgy and training for contemporary puppetry

Mario Ferreira Piragibe ${ }^{2}$ 


\section{Resumo}

O artigo propõe discutir as funções de objeto, corpo e espaço no Teatro de Animação contemporâneo. Os principais assuntos da apresentação são: discutir as origens dramatúrgicas das transformações formais da linguagem do Teatro de Animação ao longo das últimas décadas e, ao abordar mais precisamente os elementos objeto, corpo e espaço, propor que $o$ ator animador seria um elemento catalisador das dinâmicas e dos significados de tais elementos sobre a cena. Tal discussão encaminha uma compreensão entrelaçada entre processos de criação e de formação do artista, e a provocação se encerra apresentando uma lista de perguntas relativas a formação para o ator no Teatro de Animação contemporâneo.

Palavras-chave: Teatro de Animação; teatro de bonecos; dramaturgia; formação em teatro de animação; bonequeiro

\section{Abstract}

The article proposes a discussion about the functions of object, body and space to contemporary puppetry. The two main issues of the presentations are: discuss the dramaturgic origins of the formal transformations seen in puppetry through the past decades and, as approaching the matter of object, body and space, suggest that the puppeteer performer would be a catalyst to the dynamics and meanings of such elements on stage. The discussion approaches then a mixed understanding between creative processes and artist training, so the provocative presentation end showing a list of questions regarding training for contemporary puppetry.

Keywords: Puppetry; Puppet Theatre; Puppetry training; playwright; Training for puppetry; puppeteer

ISSN: 1414.5731

E-ISSN: 2358.6958

\footnotetext{
1 Este artigo é a correção e ligeira ampliação da apresentação feita em 22 de junho de 2017 no Teatrui Toni Boulandra, na cidade de Targoviste, Romênia, para a 2nd International Conference on Training for Puppetry Art, organizada pela Comissão de Formação Profissional na União Internacional da Marionete (UNIMA). O título a mim sugerido - e registrado no material informacional do evento - foi: "Funções do objeto animado, o corpo e o espaço no teatro de Animação Contemporâneo". Ainda que fosse de meu interesse manter alguma fidelidade ao tema proposto, a leitura do artigo provará que a reelaboração de seu título foi ditada por uma necessidade de coerência

${ }^{2}$ Prof. Dr. Curso de Teatro - Instituto de Artes (IARTE). Universidade Federal de Uberlândia (UFU). Ator. mpiragibe@gmail.com
} 
The notion that puppets are inanimate creatures controlled by human beings is incorrect, and the position is just the opposite: the artist is at mercy of its puppets.

(Walter Wilkinson)

Tanto corpo como espaço podem ser percebidos como objetos (Hadass Ophrat)

Creio estar aqui hoje com a função de instigar uma discussão que se entenda frutífera acerca dos papéis desempenhados por três elementos que são: objeto, corpo, e espaço para o Teatro de Animação contemporâneo. Assim, calçando as botas do provocador, tomarei a liberdade de fazer algumas declarações inconsequentes, juntamente com outras conclusões um tanto óbvias e repisadas. O objetivo é o de engatilhar uma troca de ideias sobre funções e significados dos elementos mencionados, assim como as relações que mantém com as concepções de sujeito e objeto para o Teatro de Animação contemporâneo. Por fim, e como se já não fosse bastante, encadearei algumas perguntas sobre formação para o Teatro de Animação, pois me parece muito difícil, quase impossível, compreender uma divisão clara entre a poética e a formação do artista no Teatro de Animação, e não me refiro apenas às experimentações mais contemporâneas, porque essas questões podem ser perfeitamente encontradas nas tradições dos teatros de bonecos e nos mais variados ambientes de educação para a arte. Tratarei mais das minhas dúvidas e becos sem saída do que de minhas convicções, ainda que eu possa soar seguro e convicto (sobretudo em tais passagens). As estratégias que irei usar para tentar ouvi-los hoje serão algumas frases inacabadas, tantas presunções irresponsáveis, além de uma boa dose de equívocos e, acreditem: nem todos dentre estes últimos serão intencionais.

Em discussões sobre o Teatro de Animação contemporâneo muito se fala sobre os empregos de objetos e formas abstratas, o suporte de ferramentas tecnológicas que alteraram a relação dos artistas com processos de construção e apresentação, e bastante sobre as trocas que a linguagem do Teatro de Animação vem estabelecendo com movimentos de vanguarda nas artes desde finais do século XIX ${ }^{3}$. Mas um dos assuntos que parece dominar a discussão dos últimos anos diz respeito ao manipulador posto à vista, compreendido como sendo um dos traços mais proeminentes do Teatro de Animação contemporâneo. Talvez a presença simultânea sobre a cena de bonecos e atores seja o assunto mais presente em estudos, escritos e experimentos contemporâneos sobre Teatro de Animação, assim como ocorre com a variedade de efeitos e significados permitidas por tal emprego. O recurso permite a disposição de uma certa quantidade de camadas de realidades teatrais simultâneas, por vezes permite a interação direta entre animadores e bonecos, e outras tantas propõe uma fusão indiscernível entre os corpos de artistas, objetos e materiais.

No entanto, parece algo problemático compreender-se a manipulação à vista como um dos principais fundamentos do Teatro de Animação contemporâneo. Não devido ao fato não ser verdade, posto que basta uma simples verificação do

\footnotetext{
3 Há uma série de bons artigos e livros abordando o assunto, dentre os quais posso destacar os seguintes trabalhos de Didier Plassard e Henryk Jurkovski: Jurkovski Henryk. La marioneta literaria. De Maeterlink A Ghelderode. Revista PUCK - El títere y las otras artes, ano 1, no.1. Bilbao: Institut International de la Marionnette / Centro de documentación de títeres de Bilbao, 1991 pp.4-7. Didier Plassard. L'acteur en effigie. Lausanne: L'Age D’Homme: Institut International de la Marionnette, 1992 (Théâtre années vingt).
} 
repertório atual para se verificar o quanto o recurso é difundido e importante para o atual panorama, mas principalmente pelo fato de o recurso parecer ser, de fato, um desdobramento visível de uma transformação mais importante, que se deu no âmbito temático e dramatúrgico.

Se nos reportarmos aos trabalhos de artistas e companhias famosos pela exploração da coabitação de manipuladores/performers e bonecos/objetos, tais como Philippe Genty, Mossoux-Bronté, Dos a Deux, Hugo e Ines, Ilka Schonbein, e muitos outros, é possível perceber que o impacto principal de suas apresentações não se apoia no simples emprego da coabitação, mas nas maneiras como esta é explorada para apresentar questões relativas a identidade, sofrimento psicológico, violência, onirismo, ambiguidade, e assim por diante.

Recentemente travei contato com o trabalho de Paul Piris, mais precisamente um texto escrito para a Routledge Companion of Puppetry and Material Performance, no qual o autor afirma que "a renovação do Teatro de Animação ao longa das últimas décadas é o resultado de uma exploração do sentido dramatúrgico da figura animada no teatro"4 (Piris, 2014, p.30). Se ao longo das últimas décadas os significados do boneco em cena passaram por algumas mudanças ou, ao menos, viram suas possibilidades ampliadas, tal se deu devido a uma mudança nos entendimentos dos indivíduos acerca de si mesmos, e nas maneiras como o boneco poderia apresentar algumas metáforas eloquentes apoiadas nessa nova visão.

Steve Tillis menciona que "falar de uma pessoa, metaforicamente, como sendo um fantoche ${ }^{5}$ equivale a referir-se a esta pessoa com um certo grau de desprezo. [...] Ser chamado de fantoche não é apenas ser rotulado com um termo desagradável, mas também ter sua condição ontológica submetida uma dúvida desdenhosa" (1992, p.168). Quase toda a discussão acerca de subjetividade, personalidade e identidade em nossos tempos conduzidas por alguns pensadores proeminentes, dentre os quais poderia citar Zygmunt Bauman e Stuart Hall como exemplos, abordam o fato de que ambiguidades, incertezas, fluidez e as mais variadas dúvidas acerca de questões existenciais, não seriam apenas falhas do comportamento humano, mas componentes de fato, fios significativos do tecido que compõe a personalidade e os modos de relacionamento humano na atualidade.

Praticamente todos os espetáculos realizados pela Cie Philippe Genty exploram combinações entre bonecos, objetos e artistas de modo a construir ambientes oníricos, nos quais as experiências de seu diretor entrechocam-se com as de seus espectadores por meio de imagens arquetípicas e da exposição de tensões seminais.

A Cia Dos à Deux faz uso de bonecos que são fragmentos de corpos humanos acoplados a peças de mobília e aos atores-bailarinos, com o fito de apresentar variados estágios do comportamento humano, de produzir quadros que abordam a condição humana e para encenar a violência que indivíduos dispensam a si mesmo e aos outros ${ }^{6}$.

\footnotetext{
4 "The renewal of puppetry over the past decades is the result of an exploration of the dramaturgical meaning of the animated figure in the theatre". (Tradução nossa) ${ }^{5}$ A tradução mais precisa do termo empregado por Tillis, puppet, seria boneco. Opto aqui pelo termo fantoche para o termo em português que remete mais claramente ao jogo de palavras proposto pelo autor.

${ }^{6}$ Essas características podem ser bem percebidas em espetáculos da referida companhia tais como Fragmentos do Desejo (2009) e Gritos (2016).
} 
A montagem de Peer Gynt, de Henryk Ibsen, feita pela PeQuod Teatro de Animação (2006) alternou atores e bonecos de modo a discutir a ambiguidade de caráter e inconsistência existencial do personagem-título. Ao optar por apresentar a personagem por meio da alternância entre ator, boneco e a combinação dos dois, abordou-se a sua falta de integridade (em todos os sentidos), criando-se também outra tensão diante do espectador: a que se estabelece entre a personagem individual, paciente da sua história, vivendo-a em tempo presente, e a mesma personagem que narra (ou recorda) a história, descolada das amarras de espaço e tempo às quais as recriações artísticas não devem muitas satisfações.

Parece que a imagem instável e fragmentária atribuída ao indivíduo contemporâneo encontrou no boneco uma representação artística bastante adequada e, mais que isso, que tal identificação se deu com tal radicalidade que, no processo, o próprio boneco se viu alterado. Muitos bonecos contemporâneos são orgulhosamente grotescos, intencionalmente incompletos e propõem discussões acerca da condição humana em meio ao próprio ato de afastar-se de sua forma genérica.

Cariad Astles trata do que ela chama de "perda" dos corpos dos bonecos, ainda que elabore um pensamento bastante diverso para suas causas e consequências:

[...] o boneco propriamente dito tem se tornado um artigo difícil de se encontrar em meio a trabalhos que se apresentam como "teatro de bonecos"; ao invés disso, o corpo do boneco tem sido substituído por corpos de múltiplas articulações criado de diferentes maneiras, o que produz seus próprios significados. Quero dizer com isso que a figura unificada do boneco tem sido substituída em muitos casos por sombras, projeções e tecnologias multimídia; por objetos (Astles, 2009, p.62) $)^{7}$.

E assim chegamos às questões relativas a corpo, objeto e espaço, uma vez que tais elementos se tornaram os apoios sobre os quais se assenta o Teatro de Animação contemporâneo ou, em outras palavras: o que é de fato animado/ganha relevância cênica no contexto contemporâneo, após a perda do corpo do boneco.

Tenho apreço particular por uma passagem do livro Towards an Aestethics of the Puppet (1992), de Steve Tillis, na qual o autor aponta que um boneco pode ser definido por aquilo que o público compreende como sendo um boneco. Eis a citação:

[...] quando as pessoas mencionam o boneco teatral, estão se referindo a elementos que são reconhecidos por uma plateia como sendo objetos aos quais são conferidos forma, movimento e, frequentemente, fala, de uma maneira tal que essa plateia os imagina como possuidores de uma vida (Tillis, 1992, p. 28). ${ }^{8}$

A noção de vida, como apresentada por Tillis, pode ser de fato lida de diferentes maneiras. Não irei abordar essa questão terminológica, por hora, mas chamarei atenção para dois pontos interessantes contidos na declaração, que são:

\footnotetext{
7 "[...] the puppet itself has frequently become hard to locate within work which designates itself as 'puppet theatre'; instead, the puppet body has been replaced by a multiply articulated body created from different sources, which generates its own meaning. By this I mean that the unified puppet figure has been replaced in many cases by shadows, projections and multimedia technology; by objects; by matter; and by animated scenic action which creates its own perception of a puppet 'body'. (Tradução nossa)

8 "[...] when people talk about puppets, they are talking about figures perceived by an audience to be objects that are given design, movement, and frequently, speech, in such a way that the audience imagine them to have life". (Tradução nossa)
} 
(1): O boneco é um fenômeno de percepção, e eu diria ainda: é um coup l' oeil teatral. Ainda, Tillis sugere que é a plateia quem tem a última palavra sobre a questão do que poderia ser considerado um boneco. Esse entendimento nos convida a deixar de pensar que o boneco teatral seria o resultado de uma certa quantidade de características formais e estruturais postas juntas, para buscar considerá-lo como sendo o resultado de uma cadeia de efeitos produzidos pela visão, audição e interpretação de sinais. É importante perceber, também, que um boneco teatral é algo percebido como possuidor de sentido ontológico (ou seja, desempenha um papel) dentro de um contexto teatral (mais precisamente dramático) ${ }^{9}$.

(2): Se o boneco é um fenômeno de percepção captado pela plateia, que reconhece nele um objeto que apresenta um sujeito em um contexto teatral, desta forma poderia ser correta a afirmação de que não há limites em termos de forma e estrutura para se apresentar bonecos, mas também que há uma série de instâncias de mediação, além de forma e matéria que podem ser incorporadas ao conjunto de percepções que formam o boneco. A proposta poderia ser aprofundada (e ligeiramente corrigida) da seguinte maneira: se há limites formais e estruturais para o que poderia ser considerado boneco, estes não são ditados pelos métodos e materiais de construção, mas pelos modos de percepção e leitura, e esses dois processos (construção e percepção) nem sempre entram em acordo, obviamente.

Espaço e corpo são termos um tanto amplos, e que podem ser usados e combinados indefinidamente. O mesmo se dá ao empregarmos essas palavras para tratar de Teatro de Animação. Buscarei assim objetivar esta discussão e abordar algumas dinâmicas sobre a apresentação de bonecos e formas animadas no contexto contemporâneo.

Mencionei anteriormente que o Teatro de Animação se tornou uma plataforma eloquente de discussão das concepções contemporâneas de identidade e de entendimentos do self, e gostaria de apontar duas ou três justificativas para isso:

a) é amplamente mencionado o quanto o Teatro de Animação lida com situações e imagens que ultrapassam barreiras da física e da lógica. Mais que isso, dá forma e movimento a abstrações e transforma metáforas em presença material. O Teatro de Animação oferece corpos a ideias e transforma objetos em corpos na medida em que confere a eles significado dramatúrgico. Sempre que adequadamente posto no espaço, tornado presente e dotado de contexto por meio da animação, o objeto-corpo é capaz de produzir uma impressão violenta sobre a percepção da plateia, uma vez que passa a ser mais do que uma representação, mas uma corporificação ${ }^{10}$.

\footnotetext{
${ }^{9}$ Não deixa de ser, ainda assim, digno de nota o tempo que muitos estudiosos dedicam à tentativa de dizer o que seria ou não o boneco; ou o que poderia ou não ser considerado Teatro de Bonecos. Eu mesmo já empreguei tempo e tinta nesse esforço, posto que o exercício nos ajuda a compreender as transformações da linguagem ao longo do tempo, bem como selecionar e identificar procedimentos e formas em meio a processos de criação e ensino. Mas a pergunta invariavelmente nos conduz a lidarmos com a sua função (qual o sentido de se determinar se um objeto ou um espetáculo se enquadra nesta ou naquela categoria?), sobretudo quando desvia o nosso olhar de entendimentos relevantes para a o próprio Teatro de Animação, bem como de peças teatrais muito interessantes.

10 Talvez eu leve algum tempo até ajustar o emprego desta palavra. No original inglês do texto foi usado o termo embodiment, que apresenta o sentido justo de conferir corpo a algo. Evitei a todo custo empregar palavras como encarnação ou incorporação, empregadas usualmente em contextos que poderiam desviar o sentido inicial da ideia que se pretende apresentar.
} 
b) Não se deve, no entanto, compreender essa corporificação como relacionado a produção de ilusão; a apresentação de um boneco porta uma contradição existencial evidente, a qual Piris (2014, p. 30) chama de ambiguidade ontológica, e pode produzir sobre a percepção da plateia aquilo que Tillis denomina efeito de visão dupla (1992), que vem a ser o entendimento simultâneo de que se está diante de algo que não é um ser integral, de vida independente, mas que percebemos - decidimos perceber - como se assim fosse. O curioso é que essa ambiguidade revelada não produz, usualmente, o efeito de afastar nossa atenção da apresentação, mas fortalece o seu apelo, na medida em que distende a nossa percepção da realidade e oferece representações críticas e tensas dos sujeitos, posto que põem em confrontos os termos nos quais se assentam suas presenças e existências.

O efeito de visão dupla, causa e consequência da ambiguidade ontológica do boneco é talvez a causa principal da manutenção do interesse sobre o Teatro de Bonecos ao longo dos anos, mas também o motivo da sua adequação para lidar com representações mais atuais do self e das relações humanas. Sua vocação nata para a metaficcionalidade, juntamente com a sua capacidade de reconstruir o corpo natural para apresenta-lo com outros arranjos permite que se mostre assim o diferente, 0 grotesco, o estranho ${ }^{11}$.

Assim, a partir desse contexto, é possível reconhecer o artista manipulador de bonecos posto à vista como um dos principais recursos da dramaturgia contemporânea do Teatro de Animação. Não apenas porque aplica tensão às relações entre corpos e materiais, mas porque afeta a própria estrutura da narrativa cênica. Cito aqui Hadass Ophrat (2002, p. 31):

A exposição do bonequeiro e da técnica de manipulação criaram uma nova narrativa, essencialmente pós-modernista, que reescreveu o drama para o Teatro de Bonecos. A ênfase moveu-se do drama narrativo para a história-dentro-da-história ${ }^{12}$.

O ator-manipulador posto à vista funciona como catalisador dos elementos dramatúrgicos apresentados em cena. Ele amplifica questões acerca da existência por meio da afirmação de uma relação de si a outro estabelecida com materiais, objetos e efeitos teatrais - e isto pode ser perfeitamente verificado nos trabalhos de Neville Tranter, por exemplo. Ele também promove conexões entre diferentes elementos da cena, conferindo-lhes sentido e integrando-os em um contexto comum. Esse artista desempenha um papel fundamental na conexão entre tempos e espaços, e na condução das ênfases de toda a narrativa da cena; é o elemento dinâmico que negocia os sentidos do ambiente heterogêneo que é a cena no Teatro de Animação contemporâneo.

O ator no Teatro de Animação contemporâneo manipula mais que os bonecos; manipula também o espaço e o sentido de unidade da apresentação. Nas palavras de Plassard (1992, p. 19):

\footnotetext{
${ }^{11}$ O termo escolhido para a versão em inglês desse artigo foi uncanny, o que é uma alusão direta ao conceito do uncanny valley, criado pelo roboticista japonês Masahiro Mori, a partir da teoria de que réplicas humanas provocariam aversão a partir de um determinado nível de semelhança com o ser humano. Há uma explicação dessa teoria em: Zaven Paré. O robô e a maçã. Rio de Janeiro: 7Letras, 2009.

12 "Exposing puppeteer and manipulation technique created a new essentially post-modernist narrative that has rewritten puppet-theatre drama. Emphasis has shifted from narrative drama to story-whithin-story". (Tradução nossa)
} 
Alternadamente narrador e personagem, sobrepondo-se à ação e deslizando sobre ela, o ator torna-se o lugar de uma dissociação entre os diferentes planos da representação; ao mesmo tempo em que molda, pode fazer desaparecer os intérpretes de seu drama ${ }^{13}$.

Eu não me atreveria a dizer que manipula a atenção e as expectativas da plateia, pois creio que esta capacidade está entre aquelas que todo artista da cena deveria cultivar. Mas creio poder sugerir que o contexto contemporâneo nos apresentou a algumas formas de manipulação que não se apoiam tão fortemente sobre o controle articular do boneco. Poderíamos argumentar que os usos da voz e da narração se ampliaram, que outras perspectivas de como conferir relevância cênica a materiais inertes surgiram, e sobretudo, que houve um aumento das iniciativas artísticas que lidam com uma ampla variedade de formas e linguagens do Teatro de Animação ao mesmo tempo, na mesma apresentação.

Entendimentos como este acerca do ator no teatro de animação contemporâneo apresentam alguns desafios à comunidade acadêmica relativas a formação, já que se trata de uma arte de múltiplas manifestações, muitas das quais guardando diferenças críticas em relação a outras, e tantas outras que demandam habilidades tanto complexas quanto específicas. Não podemos sobretudo deixar de considerar o fato de que estamos tratando de uma arte que mantém um vínculo duplo entre tradição e modernidade, a ponto de fazer a tentativa de se perceber suas diferenças uma tarefa árdua a qualquer um.

Assim, como foi mencionado anteriormente acerca de minhas dificuldades em distanciar questões relativas a criação e a formação em Teatro de Animação, eu gostaria de propor algumas interrogações-provocações finais relativas a treinamento e formação para o Teatro de Animação que, espero, possam encaminhar discussões futuras:

1. Como estabelecer princípios e estratégias gerais de formação do ator para uma linguagem artística heterogênea como o Teatro de Animação? É possível construir algum consenso a esse respeito?

2. Quais são as diferenças e semelhanças entre bonequeiros e atores no contexto contemporâneo?

3. Como preparar um curso ou workshop visando uma formação multicompetente?

4. As palavras que escolhemos para definir e discutir o Teatro de Animação afeta os modos como as pessoas compreendem suas formações?

5. É possível preparar-se ou exercitar-se para Teatro de Animação sem desenvolver habilidades com as mãos?

6. Devemos começar por técnicas básicas ou vontades criativas? Como equilibrar esses dois motivadores em processos com tempo reduzido?

7. Devemos começar ensinado as formas tradicionais ou as investigações contemporâneas?

\footnotetext{
13 "Tour à tour narrateur et personage, surplombant l'action et se glissant en elle, l'acteur deviant le lieu d'une dissociation entre les différents plans de la representation, en même temps qu'il façonne puis efface les interprètes de son drame". (Tradução nossa)
} 
Essa lista de perguntas, que mistura provocações retóricas com questões de interesse prático evidente, não passa de uma listagem de assuntos para suscitar uma discussão momentânea, e de fato não deve ser tomada como algo que vá muito além disso. Ainda assim reconheço em alguns tópicos específicos questões que merecem mais reflexão, como as contidas na quarta e na quinta indagação. Reconheço também que a primeira pergunta se constitui no fundamento sobre o qual se assentam meus mais duradores interesses como professor, pesquisador e artista.

\section{Referências}

ASTLES, Cariad. Alternative puppet 'bodies'. Móin-móin. Revista de estudos sobre teatro de formas animadas, ano 4, n. 5. Jaraguá do Sul: SCAR/UDESC, 2008. pp.62-8.

PIRAGIBE, Mário Ferreira. Manipulações: entendimentos e usos da presença e da subjetividade do ator em práticas contemporâneas de teatro de animação no Brasil. 2011.2. 399 f. Tese (Doutorado em Artes Cênicas) - Centro de Letras e Artes, Universidade Federal do Estado do Rio de Janeiro, Rio de Janeiro, 2011.2.

OPHRAT, Hadass. The visual narrative: stage design for puppet theatre. e pur si muove: UNIMA magazine, ano 1, no.1. Charleville-Mézières: Institut International de la Marionnette, 2002. pp. 31-3.

PIRIS, Paul. The co-presence and onthological ambiguity of the puppet. in: BELL, J.; ORENSTEIN, C.; POSNER, D. The Routledge companion to Puppetry and material perfomance. New York: Routledge, 2014. pp. 30-42.

PIRIS, Paul. La traversée des figures. Revista PUCK - La marionnette et les autres arts, ano 4, n.8. Charleville-Mézières: Institut International de la Marionnette, 1995. pp.159.

TILLIS, Steve. Towards an aesthetics of the puppet: puppetry as a theatrical art. New York: Greenwood Press, 1992.

Recebido em: 23/05/2018

Aprovado em: 23/05/2018 